\title{
Associations of a PTPNI I G/A polymorphism at intron 3 with Helicobactor pylori seropositivity, gastric atrophy and gastric cancer in Japanese
}

\author{
Asahi Hishida*1, Keitaro Matsuo ${ }^{2}$, Yasuyuki Gotoํ, Mariko Naito1, \\ Kenji Wakai ${ }^{1}$, Kazuo Tajima ${ }^{2}$ and Nobuyuki Hamajima ${ }^{1}$
}

\begin{abstract}
Address: ${ }^{1}$ Department of Preventive Medicine/Biostatistics and Medical Decision Making, Nagoya University Graduate School of Medicine, Nagoya, Japan and 2Division of Epidemiology and Prevention, Aichi Cancer Center Research Institute, Nagoya, Japan

Email: Asahi Hishida* - a-hishi@med.nagoya-u.ac.jp; Keitaro Matsuo - kmatsuo@aichi-cc.jp; Yasuyuki Goto - ygoto@med.nagoya-u.ac.jp; Mariko Naito - mnaito@med.nagoya-u.ac.jp; Kenji Wakai - wakai@med.nagoya-u.ac.jp; Kazuo Tajima - ktajima@aichi-cc.jp; Nobuyuki Hamajima - nhamajim@med.nagoya-u.ac.jp

* Corresponding author
\end{abstract}

Published: 9 July 2009

BMC Gastroenterology 2009, 9:5I doi:10.1 I86/I47I-230X-9-5 I
Received: 26 September 2008

Accepted: 9 July 2009

This article is available from: http://www.biomedcentral.com/I47|-230X/9/5 |

(C) 2009 Hishida et al; licensee BioMed Central Ltd.

This is an Open Access article distributed under the terms of the Creative Commons Attribution License (http://creativecommons.org/licenses/by/2.0), which permits unrestricted use, distribution, and reproduction in any medium, provided the original work is properly cited.

\begin{abstract}
Background: Previous studies have revealed the significance of Helicobacter pylori $(H$. pylori) infection as a risk factor of gastric cancer. Cytotoxin-associated gene A ( $\operatorname{cag} A)$ positivity has been demonstrated to determine the clinical outcome of $H$. pylori infection in the presence of SHP-2 (src homology 2 domain-containing protein tyrosine phosphatase-2). This study aimed to examine the formerly reported association of G/A PTPNII (proteintyrosine phosphatase, nonreceptor-type II) polymorphism (rs2301756) with gastric atrophy, as well as the association with gastric cancer in a Japanese population using a large sample size.

Methods: Study subjects were 583 histologically diagnosed patients with gastric cancer (429 males and I54 females) and age- and sex-frequency-matched I,636 non-cancer outpatients (I,203 males and 433 females), who visited Aichi Cancer Center Hospital between 200I-2005. Serum anti-H. pylori IgG antibody and pepsinogens were measured to evaluate $H$. pylori infection and gastric atrophy, respectively. Odds ratios (ORs) and $95 \%$ confidence intervals $(\mathrm{Cls})$ were calculated by a logistic model.

Results: Among $\mathrm{H}$. pylori seropositive non-cancer outpatients, the age- and sex-adjusted $\mathrm{OR}$ of gastric atrophy was $0.82(95 \% \mathrm{Cl} 0.62-\mathrm{I} . \mathrm{I} 0, P=0.194)$ for $G / A, 0.84(95 \% \mathrm{Cl} 0.39-\mathrm{I} .8 \mathrm{I}, P=0.650)$ for $A / A$, and $0.83(95 \% \mathrm{Cl} 0.62$ $1.09, P=0.182)$ for $G / A+A / A$, relative to $G / G$ genotype, and that of severe gastric atrophy was $0.70(95 \% \mathrm{Cl} 0.47-$ I.04, $P=0.079), 0.56$ (95\% Cl 0.17-I.9I, $P=0.356)$, and 0.68 (95\% Cl 0.46-I.0I, $P=0.057$ ), respectively. Among $H$. pylori infected subjects $(H$. pylori seropositive subjects and seronegative subjects with gastric atrophy), the adjusted OR of severe gastric atrophy was further reduced; $0.62(95 \% \mathrm{Cl} 0.42-0.90, P=0.012)$ for $G / A+A / A$. The distribution of the genotype in patients with gastric cancer was not significantly different from that for $H$. pylori infected subjects without gastric atrophy.

Conclusion: Our study results revealed that those with the A/A genotype of PTPNII rs230I756 polymorphism are at lower risk of severe gastric atrophy, but are not associated with a decreased risk of gastric cancer, which partially supported our previous finding that the polymorphism in the PTPNII gene encoding SHP-2 was associated with the gastric atrophy risk in $H$. pylori infected Japanese. The biological roles of this PTPNII polymorphism require further investigation.
\end{abstract}




\section{Background}

Helicobacter pylori (H. pylori) infection is a well-established risk factor of gastric cancer through the development of gastric atrophy and subsequent precancerous lesions. Particularly, $H$. pylori strains with the cytotoxin-associated gene $\mathrm{A}(\mathrm{cagA})$ are in a strong association with increased gastric adenocarcinoma risk [1]. Severe gastric atrophy and corpus-predominant gastritis along with intestinal metaplasia are well established as predominant predispositions to gastric cancer [2]. Host proinflammatory genetic factors in combination with bacterial virulence factors such as CagA have been reported to determine the severity of gastric damage and the eventual clinical outcome of $\mathrm{H}$. pylori infection $[3,4]$. The risk of gastric cancer is multiplied several fold if the host harbors both of these factors $[5,6]$. In East Asian populations, great majority of $H$. pylori are cagA-positive strains. CagA is divided into two major subtypes, East Asian type and Western type [7]. The grade of gastric atrophy and gastric cancer risk is higher in patients with East Asian cagA-positive strains than in those with cagA-negative or Western cagA-positive strains [8].

CagA protein is translocated from attached $H$. pylori into host gastric epithelial cells via a bacterial type IV secretion apparatus, and undergoes tyrosine phosphorylation in the host cells [9]. It induces the scattering phenotypes in gastric epithelial cells, called the "hummingbird phenotype," which is thought to play a crucial role in the pathogenesis of cagA-positive H. pylori infection, eventually leading to gastric carcinoma. In this CagA-dependent morphological transformation of gastric epithelial cells, the existence of SHP-2 (src homology 2 domain-containing protein tyrosine phosphatase-2) is essential [10]. SHP-2 plays a key role in intracellular signaling downstream of a number of growth factors, hormones, and cytokines [11,12]. The translocated CagA forms a physical complex with SHP-2 thereby stimulating its phosphatase activity [10]. Subsequent Erk (extracellular signal-regulated kinase) activity also contributes to the CagA-induced "hummingbird phenotype" [13]. Thus, CagA/SHP-2 complex formation may induce abnormal proliferation, movement of gastric epithelial cells and cellular changes that might conclusively lead to gastric atrophy and gastric carcinoma.

Since SHP-2 closely interacts with the CagA protein, it is natural to speculate that functional polymorphisms in the PTPN11 (protein-tyrosine phosphatase, nonreceptor-type 11) gene encoding SHP-2 may ultimately influence the degree of gastric atrophy and transformation to gastric cancer in infected subjects. There are 9 single nucleotide polymorphisms (SNPs) at minor allele frequency $>0.05$ in PTPN11 gene in Japanese on HapMap, all of which are located in non-coding regions, and most of them are in absolute linkage disequilibrium (LD) $\left(D^{\prime}=1\right.$ and $\left.r^{2}=1\right)$ or complete linkage disequilibrium $\left(D^{\prime}=1\right.$ and $\left.r^{2}<1\right)$ to each other. Five of the 9 SNPs are shown to be in complete
LD and 3 of them are shown to be in absolute LD or nearly absolute $\mathrm{LD}\left(D^{\prime}=1\right.$ and $\left.r^{2}>0.9\right)$ in Caucasians as shown in Figure 1, based on HapMap homepage http:// www.hapmap.org. Our recent report revealed that one PTPN11 G/A SNP at intron 3 (rs2301756) was in complete LD to another PTPN11 G/A SNP at intron 10 (rs12229892) [14]. In this study, the G/A SNP at intron 3 (rs2301756), one of the 3 SNPs in absolute LD was selected as a representative of these linked SNPs.

In $H$. pylori related gastric cancer, the process leading to disease has three steps; $H$. pylori infection, gastric atrophy development and carcinogenesis. At each step, genetic traits and their interactions with lifestyle may influence the process [15]. For genetic traits, significant associations of interleukin (IL) -1B C-31T and C-511T polymorphisms $[16,17]$, tumor necrosis factor (TNF)- $\alpha$ C-857T and T1031C polymorphisms [18], and a NAD(P)H dehydrogenase, quinone 1 (NQO1) C609T polymorphism [19] with $H$. pylori infection, and associations of a G/A polymorphism at intron 2 of Grb2-associated binder 1 (Gab1) [20], interleukin (IL) 2 T-330G, and IL-13 C-1111T [21] with gastric atrophy have been reported to date. Variable number of tandem repeats (VNTR) polymorphisms of mucin 1 (MUC1) have also been shown to influence $H$. pylori infection $[22,23]$. Although there are several studies to demonstrate the polymorphisms significantly associated with the risk of gastric cancer, only a few studies evaluated the risk for the step from gastric atrophy to gastric cancer [15].

In our previous studies among Japanese and Japanese Brazilians, the AA genotype in intron 3 was shown to reduce the risk of gastric atrophy development $[24,25]$. Recently, another PTPN11 SNP (rs11066322 at intron 10 in complete linkage disequilibrium to rs2301756) was found to be significantly associated with serum apoB levels in a British population [26], supporting the hypothesis that this PTPN11 polymorphism is functional. This study aimed to confirm the formerly reported association between the PTPN11 polymorphism (rs2301756) and gastric atrophy measured with serum pepsinogens in a large number of Japanese subjects, as well as to examine the association with gastric cancer risk.

\section{Methods Subjects}

Subjects were participants of HERPACC (Hospital-based Epidemiologic Research Program at Aichi Cancer Center) study, in which first-visit outpatients were consecutively invited to provide lifestyle data and blood sample after obtaining informed consent [27]. Among the participants who visited Aichi Cancer Center Hospital from 2001 2005, 583 cases diagnosed as gastric cancer and age- and sex-frequency-matched 1,638 cancer free outpatients were sampled as a control group, among whom two outpa- 


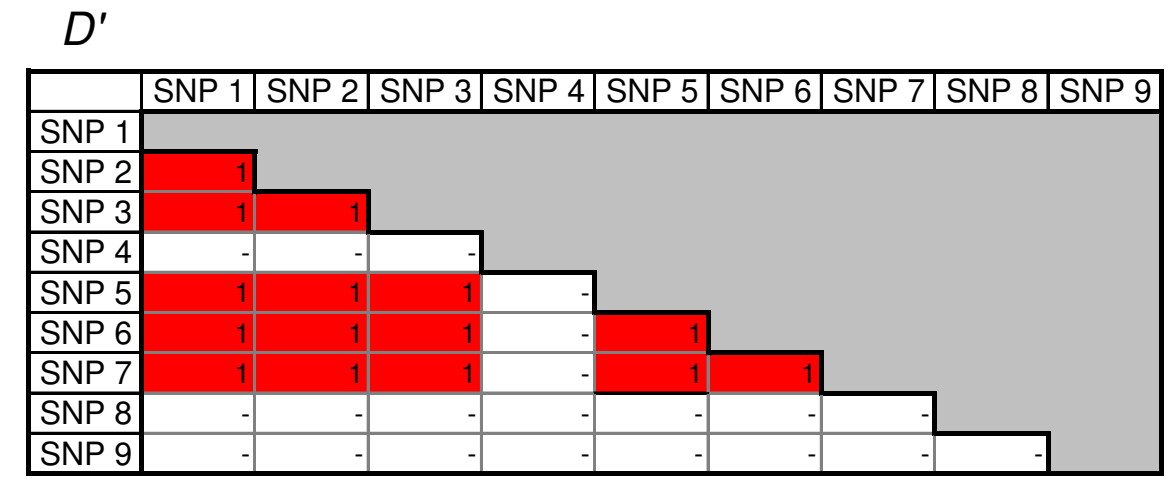

SNP 1: rs2301756

SNP 2: rs12423190

SNP 3: rs11066322

SNP 4: rs12229892

SNP 5: rs7313360

SNP 6: rs7958372

SNP 7: rs3741983

SNP 8: rs7132778

SNP 9: rs4767860
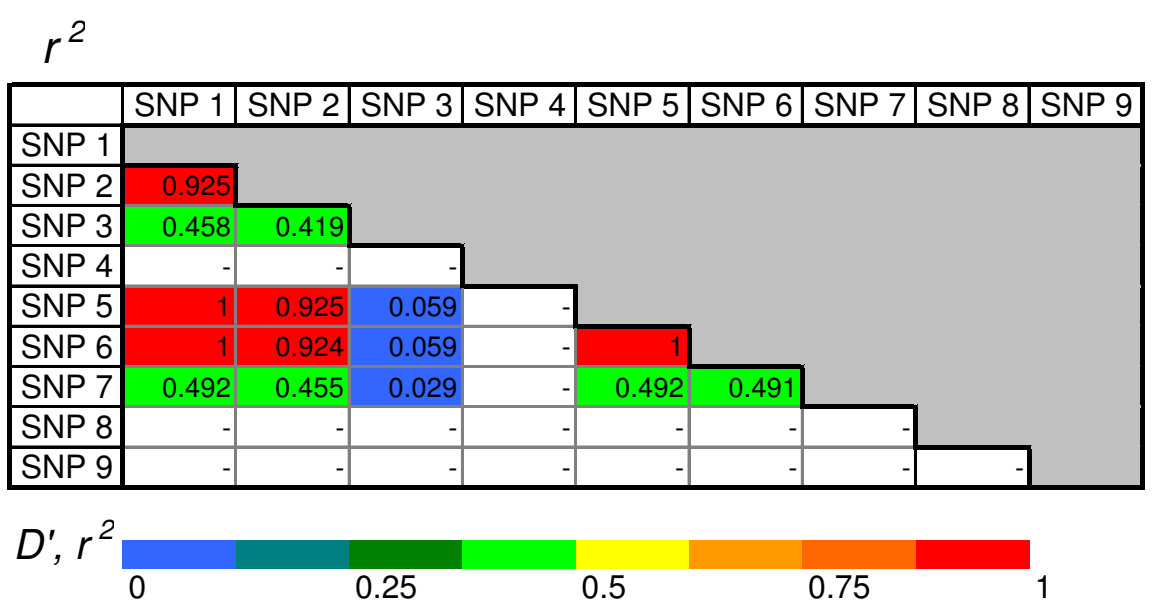

Figure I

Linkage disequilibrium (LD) between the 9 single nucleotide polymorphisms (SNPs) with a minor allele frequency $>0.05$ in the PTPNII gene region among Caucasians (CEU: Utah residents with ancestry from northern and western Europe). LD maps are shown by two parameters, $r^{2}$ and $D^{\prime}$ for Caucasians (CEU: Utah residents with ancestry from northern and western Europe). SNP numbers in the LD maps correspond to the rs numbers described in the upper right of the maps.

tients were excluded because they could not be genotyped, leaving 583 cases and 1,636 controls eligible for the analyses. Informed consent was obtained from all the subjects and the study protocol was approved by the Ethics Committees of Aichi Cancer Center and Nagoya University Graduate School of Medicine.

\section{Samples and diagnostic criteria}

Their serum samples were immediately stored at $-20^{\circ} \mathrm{C}$ until analysis. Anti-H. pylori IgG antibody was measured with an enzyme immunoassay (EIA) kit "E plate 'Eiken' $H$. pylori Antibody" (Eiken Kagaku, Tokyo, Japan). According to the instructions provided with this kit, 10.0 units or higher was regarded as seropositive. Serum pepsinogens (PG) were measured by chemiluminescence enzyme immunoassay (CLEIA). Gastric mucosal atrophy was grouped into "none" (PG I > $70 \mathrm{ng} / \mathrm{ml}$ or PG I/PG II > 3), "mild" (PG I $\leq 70 \mathrm{ng} / \mathrm{ml}$ and PG I/PG II $\leq 3$, excluding "severe" cases), or "severe" (PG I $\leq 30 \mathrm{ng} / \mathrm{ml}$ and PG I/PG $\mathrm{II} \leq 2$ ). Since serum samples of gastric cancer cases were planned to be used for a study with higher priority, the antibody and PGs of the cases were not measured.

\section{Genotyping}

DNA was extracted from buffy coat using the Qiagen DNeasy mini kit (Qiagen, Hilden, Germany). The PTPN11 G/A polymorphism (rs2301756) was genotyped with a polymerase chain reaction with confronting twopair primers (PCR-CTPP) [28]. The primers were F1: GGA TTA CAG GCA TAA GCC AC, R1: GAC CAC TAA ACT TCT TAA ATG AGC, F2: CAT TTG TCT CTA AAG GAC TGT GGA, and R2: CTC TGG CTC TCT CGT ACA AGA. Amplification conditions were $10 \mathrm{~min}$ of initial denaturation at $95^{\circ} \mathrm{C}$, followed by 30 cycles of $1 \mathrm{~min}$ at $95^{\circ} \mathrm{C}, 1 \mathrm{~min}$ at $64^{\circ} \mathrm{C}$, and $1 \mathrm{~min}$ at $72^{\circ} \mathrm{C}$, then a 5 -min final extension at $72^{\circ} \mathrm{C}$. The amplified DNA was visualized on a $2 \%$ agarose gel with ethidium bromide staining. The amplified DNA was 201 bp for $G / G$ genotype, 201 bp and 339 bp for $G / A$ genotype, $339 \mathrm{bp}$ for $A / A$ genotype, and $490 \mathrm{bp}$ for common band [24]. 


\section{Statistical analysis}

The differences in proportions were examined with a Fisher's exact test. The 95\% confidence intervals (CIs) for percentages were calculated based on binomial distributions. Logistic regression analysis was performed for estimating odds ratios (ORs) and 95\% CIs. Age was adjusted as a continuous variable in the logistic model. $H$. pylori infected subjects was defined as those with $H$. pylori seropositivity or with gastric atrophy, because in the great majority of cases gastric atrophy develops after $H$. pylori infections. The trends for $H$. pylori infection, gastric atrophy or gastric cancer development by sex or age categories were compared using the $\chi^{2}$ test for trend. The calculations were done using the STATA version 7 (Stata Corp, College Station, TX).

\section{Results Characteristics of the subjects and allele frequency of the PTPNI I polymorphism}

The characteristics of the subjects are summarized in Table 1 . The mean age \pm standard deviation was $58.7 \pm 10.6 \mathrm{y}$ (range: $25-84 \mathrm{y}$ ) for controls and $58.8 \pm 10.5 \mathrm{y}$ (range: $27-80$ y) for cases. Females were $26.5 \%$ in controls and $26.4 \%$ in cases. About three quarters of the controls were infected with $H$. pylori, while about one third of the controls had gastric atrophy. The genotype frequency of the PTPN11 polymorphism among the controls was in Hardy-Weinberg's equilibrium $\left(\chi^{2}=0.047, P=0.828\right)$. We tested the trend for $H$. pylori infection, gastric atrophy or gastric cancer development by sex or age categories, which revealed significant trend for higher $H$. pylori infection rate in males $(P$-value for trend $<0.001)$ and higher age cate- gories $(P<0.001)$, and for higher prevalence of gastric atrophy in higher age categories $(P<0.001)$.

\section{PTPNI I polymorphism, H. pylori seropositivity, gastric atrophy and gastric cancer}

There was no significant association between the PTPN11 polymorphism and the seropositivity, although the OR of A/A genotype was 1.19 relative to $G / G$ genotype (Table 2).

There were $937 \mathrm{H}$. pylori seropositive subjects, among whom 495 (52.8\%) subjects had atrophy. On the one hand, there were 45 (6.4\%) subjects with atrophy among 699 seronegative subjects. The difference in the prevalence was statistically significant $(P<0.001)$.

Table 3 shows the genotype distribution according to seropositivity and atrophy. There were no subjects with A/ A genotype among the seronegative atrophy participants. Accordingly, the adjusted OR of gastric atrophy among the seronegative subjects was not calculable for the $A / A$ genotype; the genotype distribution was not significantly associated with gastric atrophy by a $3 \times 3$ Fisher's exact test $(P=0.196)$.

The age- and sex-adjusted OR of gastric atrophy among $H$. pylori seropositive subjects was 0.82 (95\% CI 0.62-1.10, $P$ $=0.194)$ for $G / A, 0.84$ (95\% CI $0.39-1.81, P=0.650)$ for $A / A$, and 0.83 (95\% CI $0.62-1.09, P=0.182$ ) for $G / A+A /$ $A$, compared with $G / G$ genotype. The age- and sexadjusted OR of severe gastric atrophy among $H$. pylori seropositive subjects was 0.70 (95\% CI $0.47-1.04, P=$ 0.079 ) for $G / A, 0.56$ (95\% CI $0.17-1.91, P=0.356)$ for $A /$

Table I: Characteristics of the subjects and the PTPNII rs230I756 polymorphism.

\begin{tabular}{|c|c|c|c|c|}
\hline & \multicolumn{3}{|c|}{ Controls $n=1636$} & \multirow[t]{3}{*}{ Cases $n=583$} \\
\hline & \multirow[t]{2}{*}{ H. pylori (-) } & \multicolumn{2}{|c|}{ H. pylori (+) } & \\
\hline & & GA (-) & GA (+) & \\
\hline$n$ & 699 & 442 & 495 & 583 \\
\hline \multicolumn{5}{|l|}{ Sex } \\
\hline Male & $479(68.5 \%)$ & $363(82.1 \%)$ & $36 \mid(72.9 \%)$ & 429 (73.6\%) \\
\hline Female & 220 (31.5\%) & $79(17.9 \%)$ & $134(27.1 \%)$ & I54 (26.4\%) \\
\hline \multicolumn{5}{|l|}{ Age } \\
\hline$<30$ & $6(0.9 \%)$ & $\mathrm{I}(0.2 \%)$ & I (0.2\%) & $2(0.3 \%)$ \\
\hline $30-39$ & 67 (9.6\%) & $\mathrm{II}(2.5 \%)$ & $3(0.6 \%)$ & $31(5.3 \%)$ \\
\hline $40-49$ & $138(19.7 \%)$ & $54(12.2 \%)$ & $31(6.3 \%)$ & 64 (11.0\%) \\
\hline $50-59$ & $194(27.8 \%)$ & $151(34.2 \%)$ & $14 \mid(28.5 \%)$ & $214(36.7 \%)$ \\
\hline $60-69$ & $211(30.2 \%)$ & $152(34.4 \%)$ & $221(44.7 \%)$ & 166 (28.5\%) \\
\hline $70-$ & 83 (II.9\%) & 73 (16.5\%) & $98(19.8 \%)$ & $106(18.2 \%)$ \\
\hline \multicolumn{5}{|c|}{ Genotype } \\
\hline$G / G$ & $483(69.1 \%)$ & $293(66.3 \%)$ & $350(70.7 \%)$ & 396 (67.9\%) \\
\hline$G / A$ & $198(28.3 \%)$ & $135(30.5 \%)$ & $131(26.5 \%)$ & 174 (29.9\%) \\
\hline$A / A$ & $18(2.6 \%)$ & $14(3.2 \%)$ & $14(2.8 \%)$ & $13(2.2 \%)$ \\
\hline
\end{tabular}

$\mathrm{GA}(-)$ and $\mathrm{GA}(+)$ indicate without atrophy and with atrophy, respectively. 
Table 2: Odds ratios (ORs) and 95\% confidence intervals (Cls) of PTPNII rs230 I756 polymorphism for $\mathrm{H}$. pylori seropositivity.

\begin{tabular}{|c|c|c|c|c|c|c|}
\hline Genotype, allele & $n$ & H. pylori + & H. pylori + (\%) & OR $^{\mathbf{a}}$ & $95 \% \mathrm{Cl}$ & $P$ value \\
\hline$G / G$ & 1126 & 643 & 57.1 & I & Reference & - \\
\hline$G / A$ & 464 & 266 & 57.3 & 1.02 & $0.81-1.28$ & 0.865 \\
\hline$A / A$ & 46 & 28 & 60.9 & 1.19 & $0.64-2.22$ & 0.577 \\
\hline G & 2716 & 1552 & 57.1 & 1 & Reference & - \\
\hline$A$ & 556 & 322 & 57.9 & 1.03 & $0.85-1.25$ & 0.387 \\
\hline
\end{tabular}

aOR for each genotype was calculated by age and sex adjusted logistic regression model, and a crude OR was calculated for each allele.

$A$, and 0.68 (95\% CI 0.46-1.01, $P=0.057)$ for $G / A+A / A$ when those without severe gastric atrophy were defined as a reference (Table 4). When $H$. pylori seropositive subjects and seronegative subjects with gastric atrophy were regarded as $H$. pylori infected subjects, the age- and sexadjusted OR of severe gastric atrophy among the $H$. pylori infected was further reduced; 0.62 (95\% CI 0.42-0.90, $P$ $=0.012$ ) for $G / A+A / A$ (Table 4$)$.

Figure 2 depicts the distributions of pepsinogen I/II ratio according to PTPN11 rs2301756 genotype among $H$. pylori infected subjects with PG I $\leq 70 \mathrm{ng} / \mathrm{ml}$. In accordance with the finding that subjects with $A$ allele were at significantly reduced risk of severe gastric atrophy, the frequency of subjects with PG I/II ratio less than 2 was lower in subjects with $A$ allele than those with $G / G$ genotype.

To investigate how this polymorphism of PTPN11 contributes to the gastric carcinogenesis among the $H$. pylori infected subjects, we also calculated the OR of gastric cancer compared with $H$. pylori infected subjects without gastric atrophy. The age- and sex-adjusted OR of gastric cancer was $0.97(95 \% \mathrm{CI} 0.74-1.28, P=0.839)$ for $G / A$, $0.71(95 \%$ CI $0.33-1.53, P=0.381)$ for $A / A$, and 0.95 (95\% CI 0.73-1.23, $P=0.689$ ) for $G / A+A / A$, relative to $G /$ $G$ genotype, none of which were statistically significant (Table 5).

\section{Discussion}

This study revealed that those who harbor $A$ allele of the PTPN11 rs2301756 polymorphism at intron 3 had a significantly lower risk of severe gastric atrophy. This is in accordance with our hypothesis that gastric atrophy development after cagA-positive $H$. pylori infection was rarer among those with $A / A$ genotype than among those with
$G / G$ genotype $[24,25]$, although the significant association was observed only for severe gastric atrophy in this study. Since the biological processes in infection, atrophy development, and carcinogenesis are different [15], the association of this polymorphism with only atrophic development seemed biologically plausible.

While there was limited information on the potential function of PTPN11 polymorphisms, biological characteristics of SHP-2 have become increasingly understood. SHP-2 is one of the two existing mammalian non-transmembrane (intracellular) protein tyrosine phosphatases (PTPs) that contain src homology 2 (SH2) domains. Binding of tyrosine phosphorylated CagA to the SH2 domains is supposed to induce conformational change in SHP-2 that weakens the inhibitory interaction between PTP and $\mathrm{N}$-terminal SH2 domains, eventually leading to the activation of SHP-2 phosphatase $[10,29,30]$. The G/A polymorphism in the intron 3 of PTPN11 is located 223 base pairs upstream from exon 4, which encodes the initial part of Cterminal SH2 domain. Although the biological role of the present polymorphism is not yet clearified, the polymorphism may have some influence on the formation of PTPN11 mRNA splicing variants, of which 8 forms have been reported to date (SpliceMinor homepage developed by The Genomics \& Bioinformatics Group (GBG) of NCI: http://www.tigerteamconsulting.com/SpliceMiner/). The LD data between the PTPN11 SNPs shown in Figure 1 is that for Caucasians, and no precise information about LD in Japanese is available at present. There are also some PTPN11 SNPs whose LD status is left unknown (SNP8 and SNP9 in Figure 1). The function of the PTPN11 polymorphism at exon 3 (rs2301756) and other PTPN11 SNPs on the interaction between SHP-2 and CagA in Japanese and other ethnicities requires further investigation.

Table 3: PTPN I I rs230I756 genotype distribution according to $H$. pylori seropositivity and the grade of gastric atrophy.

\begin{tabular}{|c|c|c|c|c|c|c|}
\hline \multirow[t]{2}{*}{ Genotype } & \multicolumn{3}{|c|}{ H. pylori seronegative } & \multicolumn{3}{|c|}{ H. pylori seropositive } \\
\hline & GA (-) & GA (+) & GA (++) & GA (-) & GA (+) & GA (++) \\
\hline$G / G$ & 447 (68.3\%) & II (64.7\%) & $25(89.3 \%)$ & $293(68.4 \%)$ & $223(68.2 \%)$ & $127(75.6 \%)$ \\
\hline$G / A$ & $189(28.9 \%)$ & $6(35.3 \%)$ & $3(10.7 \%)$ & $135(28.9 \%)$ & $93(28.4 \%)$ & $38(22.6 \%)$ \\
\hline$A / A$ & $18(2.8 \%)$ & $0(0.0 \%)$ & $0(0.0 \%)$ & $14(2.7 \%)$ & $\mathrm{II}(3.4 \%)$ & $3(1.8 \%)$ \\
\hline Total & $654(100 \%)$ & 17 (100\%) & $28(100 \%)$ & $442(100 \%)$ & $327(100 \%)$ & $168(100 \%)$ \\
\hline
\end{tabular}

$\mathrm{GA}(-), \mathrm{GA}(+)$ and $\mathrm{GA}(++)$ indicate no atrophy, mild atrophy and severe atrophy, respectively. 
Table 4: Genotype frequencies for PTPNII rs230I756 polymorphism, odds ratios (ORs) and $95 \%$ confidence intervals (Cls) of gastric atrophy in the $H$. pylori seropositive subjects (a) and $H$.pylori infected subjects (b)

(a)

\begin{tabular}{|c|c|c|c|c|c|c|c|c|c|}
\hline Genotype, allele & $n$ & All gastric atrophy (\%) & OR $^{\mathbf{a}}$ & $95 \% \mathrm{Cl}$ & $P$ value ${ }^{b}$ & $\begin{array}{c}\text { Severe gastric atrophy } \\
(\%)\end{array}$ & $\mathbf{O R}^{\mathbf{b}}$ & $95 \% \mathrm{Cl}$ & $P$ value ${ }^{b}$ \\
\hline G/G & 643 & $350(54.4)$ & I & Reference & - & $127(19.8)$ & I & Reference & - \\
\hline$G / A$ & 266 & $|3|(49.2)$ & 0.82 & $0.62-1.10$ & 0.194 & $38(14.3)$ & 0.70 & $0.47-1.04$ & 0.079 \\
\hline$A / A$ & 28 & $14(50.0)$ & 0.84 & $0.39-1.81$ & 0.650 & $3(10.7)$ & 0.56 & $0.17-1.91$ & 0.356 \\
\hline$G / A+A / A$ & 294 & $145(49.3)$ & 0.83 & $0.62-1.09$ & 0.182 & $41(13.9)$ & 0.68 & $0.46-1.01$ & 0.057 \\
\hline$G$ & 1552 & 831 (53.5) & I & Reference & - & $292(18.8)$ & 1 & Reference & - \\
\hline$A$ & 322 & $159(49.4)$ & 0.85 & $0.66-1.08$ & 0.097 & 44 (I3.7) & 0.67 & $0.45-0.96$ & 0.015 \\
\hline
\end{tabular}

(b)

\begin{tabular}{|c|c|c|c|c|c|c|c|c|c|}
\hline Genotype, allele & $n$ & All gastric atrophy (\%) & OR $^{\mathbf{a}}$ & $95 \% \mathrm{Cl}$ & $P$ value ${ }^{b}$ & $\begin{array}{c}\text { Severe gastric atrophy } \\
(\%)\end{array}$ & OR $^{\mathbf{a}}$ & $95 \% \mathrm{Cl}$ & $P$ value $^{b}$ \\
\hline$G / G$ & 677 & $383(56.6)$ & 1 & Reference & - & $|5|(22.3)$ & 1 & Reference & - \\
\hline$G / A$ & 274 & $139(50.7)$ & 0.80 & $0.60-1.06$ & 0.123 & $4 I(15.0)$ & 0.63 & $0.43-0.93$ & 0.019 \\
\hline$A / A$ & 28 & $14(50.0)$ & 0.77 & $0.36-1.67$ & 0.512 & $3(10.7)$ & 0.49 & $0.14-1.67$ & 0.254 \\
\hline$G / A+A / A$ & 302 & $153(50.7)$ & 0.80 & $0.60-1.05$ & 0.106 & $44(14.6)$ & 0.62 & $0.42-0.90$ & 0.012 \\
\hline$G$ & 1628 & $905(55.6)$ & I & Reference & - & $343(21.1)$ & I & Reference & - \\
\hline$A$ & 330 & $167(50.6)$ & 0.82 & $0.64-1.05$ & 0.102 & $47(14.2)$ & 0.62 & $0.44-0.87$ & 0.005 \\
\hline
\end{tabular}

aOR for each genotype was calculated by age and sex adjusted logistic regression model, and a crude OR was calculated for each allele.

bP values less than 0.05 are shown in Italics.

Although the G allele of PTPN11 may be a part of the genetic traits to develop gastric atrophy via signal transduction from CagA, there seems to be other genetic traits involved in this process. CagA binds several molecules; Grb2, which transduces the signal to Ras-MAPK pathway causing cell proliferation, c-Met hepatocyte growth factor (HGF) receptor, which have a role of cell proliferation and motility, ZO-1, a tight-junction protein, and Par1/Mark

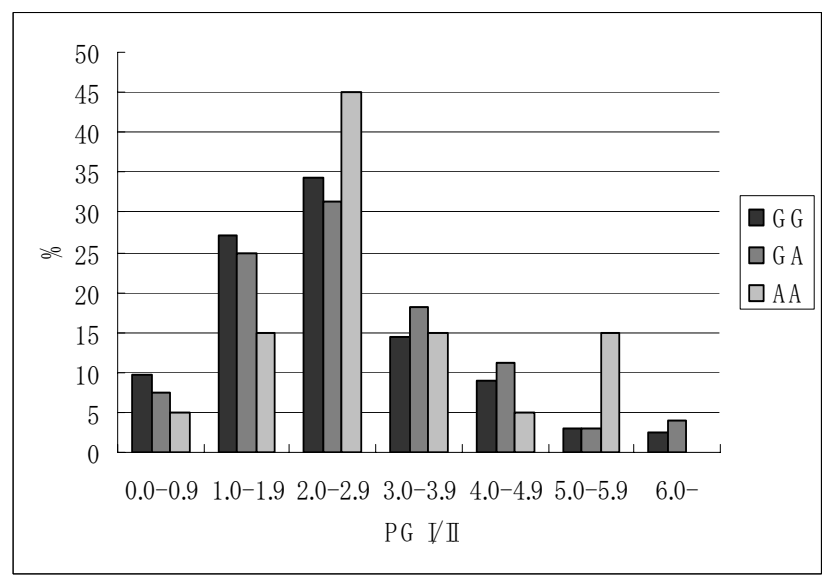

Figure 2

Distributions of pepsinogen (PG) I/II ratio according to PTPNII rs230I 756 genotype among $H$. pylori infected subjects with a PG I level of $\leq 70 \mathrm{ng} / \mathrm{ml}$. kinase, which has an essential role in epithelial cell polarity [31-35]. Although no studies have been conducted, functional polymorphisms of these molecules might be also candidates of genetic traits of gastric atrophy.

The A allele was the dominant allele of PTPN11 polymorphism at intron 3 among Caucasians ( 0.875 of 120 chromosomes), but not among Japanese (0.178 of 902 chromosomes) and Chinese (0.083 of 48 choromosomes) [26]. This study found that the $A$ allele frequency was 0.170 among our Japanese control subjects, similar to the reported allele frequency in Japanese.

The present study has several limitations. Although the $H$. pylori status of the control subjects was examined with a serology test, we did not check the CagA status. As reported in Japan, nearly $100 \%$ of $H$. pylori strains possess a functional cag pathogenicity island (cag PAI), which encodes and produces the CagA protein [36]. A previous study also certified that almost all strains isolated from our Japanese subjects were East Asian cagA-positive strains [37], indicating that $H$. pylori strains in our study subjects also possesses CagA. Another limitation is related to the diagnosis of gastric atrophy. This was done entirely on the basis of serum pepsinogen levels and not through histological assessment, because most of the control subjects did not undergo gastrointestinal endoscopy with biopsy. However, the pepsinogen method is well established as a 
Table 5: Genotype frequencies for PTPN II rs230I756 polymorphism, age-sex adjusted odds ratios (ORs) and $95 \%$ confidence intervals (Cls) of gastric cancer relative to $\mathrm{H}$. pylori infected subjects without gastric atrophy (HP-infected without atrophy).

\begin{tabular}{|c|c|c|c|c|c|}
\hline Genotype & HP infected without atrophy $n=442$ & Gastric cancer $n=583$ & OR & $95 \% \mathrm{Cl}$ & $P$ value \\
\hline$G / G$ & $293(66.3 \%)$ & $396(67.9 \%)$ & 1 & Reference & - \\
\hline$G / A$ & $135(30.5 \%)$ & $174(29.8 \%)$ & 0.97 & $0.74-1.28$ & 0.839 \\
\hline$A / A$ & $14(3.2 \%)$ & $13(2.2 \%)$ & 0.71 & $0.33-1.53$ & 0.381 \\
\hline$G / A+A / A$ & $149(33.7 \%)$ & $187(32.1 \%)$ & 0.95 & $0.73-1.23$ & 0.689 \\
\hline G & 721 (81.6\%) & $966(82.8 \%)$ & 1 & Reference & - \\
\hline$A$ & $163(18.4 \%)$ & $200(17.2 \%)$ & 0.92 & $0.72-1.16$ & 0.243 \\
\hline
\end{tabular}

aOR for each genotype was calculated by age and sex adjusted logistic regression model, and a crude OR was calculated for each allele.

surrogate marker of gastric atrophy [38-40]. The validated criterion for gastric atrophy is PG I $\leq 70 \mathrm{ng} / \mathrm{ml}$ and PG I/II ratio of $\leq 3.0$, and that for severe gastric atrophy is $P G I \leq$ $30 \mathrm{ng} / \mathrm{ml}$ and PG I/II ratio of $\leq 2.0$, both of which are supposed to be reliable because they are widely used in practice in Japan $[41,42]$. Concerning the gastric cancer cases the $H$. pylori seropositivity and pepsinogen levels were not examined, but most of the gastric cancer cases seemed to be $H$. pylori positive cases with gastric atrophy $[43,44]$. Considering that intestinal type of gastric cancer, the predominant type of gastric cancer in Japan, arises from gastric atrophy caused by $H$. pylori infection, and diffuse type gastric cancer occurs regardless of gastric atrophy [45], it would seem intriguing to perform the subgroup analysis according to these two histological types. This analysis might unveil the association of this PTPN11 polymorphism with the steps of gastric carcinogenesis more clearly. However, we could not perform this analysis because of the unavailability of the histological data. In addition, there might be several factors, including genetic, that prime the individual stomach for H. pylori colonization, which might modulate the effect of this PTPN11 polymorphism [22,23]. Further investigations with these factors taken into consideration are also expected.

\section{Conclusion}

This study revealed that rs2301756 in the PTPN11 gene encoding SHP-2 increased the risk of severe gastric atrophy in H. pylori infected subjects in Japan. Although the significant association was limited only to severe gastric atrophy, this study partially supported the roles of this PTPN11 polymorphism in the gastric atrophy development. Elucidation of the function of this polymorphism will help us understand the pathogenesis of $H$. pyloriinduced gastric cancer, which will lead to more effective means for the personalized prevention of gastric atrophy and subsequent gastric cancer in the near future.

\section{Competing interests}

The authors declare that they have no competing interests.

\section{Authors' contributions}

AH: Conducted data analysis and drafted the manuscript. KM and YG: Contributed greatly to the recruitment of the participants and data collection, and advised in preparing the manuscript. $\mathrm{MN}$ and $\mathrm{KW}$ : Contributed to data analysis, and advised in preparing the manuscript. KT and $\mathrm{NH}$ : Supervised study design, data collection and analysis, and advised in preparing the manuscript. All authors have given final approval of the version to be submitted.

\section{Acknowledgements}

The authors wish to thank all the staff involved in this study and are grateful to Ms. Yoko Mitsuda for her technical assistance. This study was supported in part by a Grant-in-Aid for Scientific Research on Special Priority Areas of Cancer from the Japanese Ministry of Education, Culture, Sports, Science and Technology.

\section{References}

I. Blaser MJ, Perez-Perez GI, Kleanthous H, Cover TL, Peek RM, Chyou PH, Stemmermann GN, Nomura A: Infection with Helicobacter pylori strains possessing cagA is associated with an increased risk of developing adenocarcinoma of the stomach. Cancer Res 1995, 55:2111-5.

2. Uemura N, Okamoto S, Yamamoto S, Matsumura N, Yamaguchi S, Yamakido M, Taniyama K, Sasaki N, Schlemper RJ: Helicobacter pylori infection and the development of gastric cancer. $\mathrm{N} \mathrm{Engl}$ J Med 200I, 345:784-9.

3. El-Omar EM, Rabkin CS, Gammon MD, Vaughan TL, Risch HA, Schoenberg JB, Stanford JL, Mayne ST, Goedert J, Blot WJ, Fraumeni JF $\mathrm{Jr}$, Chow WH: Increased risk of noncardia gastric cancer associated with proinflammatory cytokine gene polymorphisms. Gastroenterology 2003, 124: I 193-201.

4. Machado JC, Figueiredo C, Canedo P, Pharoah P, Carvalho R, Nabais S, Alves CC, Campos ML, van Doorn LJ, Caldas C, Seruca R, Carneiro $F$, Sobrinho-Simões M: A proinflammatory genetic profile increases the risk for chronic atrophic gastritis and gastric carcinoma. Gastroenterology 2003, I 25:364-7I.

5. Figueiredo C, Machado JC, Pharoah P, Seruca R, Sousa S, Carvalho R, Capelinha AF, Quint W, Caldas C, van Doorn LJ, Carneiro F, Sobrinho-Simoes M: Helicobacter pylori and interleukin I genotyping: an opportunity to identify high-risk individuals for gastric carcinoma. J Natl Cancer Inst 2002, 94(22): 1680-I 687.

6. Rad R, Prinz C, Neu B, Neuhofer M, Zeitner M, Voland P, Becker I, Schepp W, Gerhard M: Synergistic effect of Helicobacter pylori virulence factors and interleukin-I polymorphisms for the development of severe histological changes in the gastric mucosa. J Infect Dis 2003, 15:272-8I.

7. Yamaoka Y, El-Zimaity HMT, Gutierrez O, Gutierrez O, Figura N, Kim JK, Kodama T, Kashima K, Graham DY: Relationship between the cagA 3' repeat region of Helicobacter pylori, gastric histology, and susceptibility to low pH. Gastroenterol 1999, I 1 7:342-9. 
8. Azuma T, Yamazaki S, Yamakawa A, Ohtani M, Muramatu A, Suto $\mathrm{H}$ Ito $Y$, Dojo M, Yamazaki $Y$, Kuriyama M, Keida $Y$, Higashi $H$, Hatakeyama M: Association between diversity in the src homology 2 domain-containing tyrosine phosphatase binding site of Helicobacter pylori CagA protein and gastric atrophy and cancer. J Infect Dis 2004, 189:820-7.

9. Asahi M, Azuma T, Ito $S$, Ito $Y$, Suto $H$, Nagai $Y$, Tsubokawa $M$, Tohyama Y, Maeda S, Omata M, Suzuki T, Sasakawa C: Helicobacter pylori CagA protein can be tyrosine phosphorylated in gastric epithelial cells. J Exp Med 2000, 19 1:593-602.

10. Higashi H, Tsutsumi R, Muto S, Sugiyama T, Azuma T, Asaka M, Hatakeyama M: SHP-2 tyrosine phosphatase as an intracellular target of Helicobacter pylori CagA protein. Science 2002, 295:683-86

II. Neel BG, Gu H, Pao L: The 'Shp'ing news: SH2 domain-containing tyrosine phosphatases in cell signaling. Trends Biochem Sci 2003, 28:284-93.

12. Tartaglia M, Niemeyer CM, Shannon KM, Loh ML: SHP-2 and myeloid malignancies. Curr Opin Hematol 2004, I I:44-50.

13. Segal ED, Cha J, Lo J, Falkow S, Tompkins LS: Altered states: involvement of phosphorylated CagA in the induction of host cellular growth changes by Helicobacter pylori. Proc Natl Acad Sci USA 1999, 96: I 4559-64.

14. Hamajima N, Rahimov B, Malikov Y, Abdiev S, Ahn KS, Bahramov S, Kawai S, Nishio K, Naito M, Goto Y: Associations between a PTPNII polymorphism and gastric atrophy - opposite in Uzbekistan to that in Japan. Asian Pac J Cancer Prev 2008, 9:217-20.

15. Hamajima N, Naito M, Kondo T, Goto Y: Genetic factors involved in the development of Helicobacter pylori-related gastric cancer. Cancer Sci 2006, 97: I 129-38.

16. Hamajima N, Matsuo K, Saito T, Tajima K, Okuma K, Yamao K, Tominaga S: Interleukin I polymorphisms, lifestyle factors, and Helicobacter pylori infection. Jpn I Cancer Res 200I, 92:383-9.

17. Kato S, Onda M, Yamada S, Matsuda N, Tokunaga A, Matsukura N Association of the interleukin- $I \beta$ genetic polymorphism and gastric cancer risk in Japanese. J Gastroenterol 200I, 36:696-9.

18. Hamajima N, Shibata A, Katsuda N, Matsuo K, Ito H, Saito T, Tajima $\mathrm{K}$, Tominaga S: The highest Helicobacter pylori seropositive rate among those with TNF-A-857TT and - I03 ITT: genotypes. Gastric Cancer 2003, 6:230-6.

19. Goto Y, Hamajima N, Honda H, Matsuo K, Yamamoto K, Tamakosh A, Ando T, Goto H: Association between Helicobacter pylori seropositivity and $\mathrm{NAD}(\mathrm{P}) \mathrm{H}$ quinone oxidoreductase (NQOI) C609T polymorphism observed for outpatients and health checkup examinees. Gastric Cancer 2005, 8: 12-17.

20. Goto, , Ando T, Nishio K, Kawai S, Ishida Y, Naito M, Goto H, Hamajima N: Grb2-associated binder I polymorphism was associated with the risk of Helicobactor pylori infection and gastric atrophy. Int J Med Sci 2006, 4:I-6.

21. Togawa S, Joh T, Itoh M, Katsuda N, Ito H, Matsuo K, Tajima K Hamajima N: Interleukin-2 gene polymorphisms associated with increased risk of gastric atrophy from Helicobacter pylori infection. Helicobacter 2005, 10:172-8.

22. Peleteiro B, Lunet N, Santos-Silva F, David L, Figueiredo C, Barros H: Short mucin I alleles are associated with low virulent $\mathbf{H}$ pylori strains infection. World J Gastroenterol 2007, I3:1885-6.

23. Kawakubo M, Ito $Y$, Okimura $Y$, Kobayashi M, Sakura K, Kasama $S$, Fukuda MN, Fukuda M, Katsuyama T, Nakayama J: Natural antibiotic function of a human gastric mucin against Helicobacter pylori infection. Science 2004, 305: 1003-6.

24. Goto Y, Ando T, Yamamoto K, Tamakoshi A, El-Omar E, Goto H, Hamajima N: Association between serum pepsinogens and polymorphism of PTPNII encoding SHP-2 among Helicobacter pylori seropositive Japanese. Int J Cancer 2006, I I 8:203-8.

25. Kawai S, Goto Y, Ito LS, Oba-Shinjo SM, Uno M, Shinjo SK, Marie SK, Ishida Y, Nishio K, Naito M, Hamajima N: Significant association between PTPNII polymorphism and gastric atrophy among Japanese Brazilians. Gastric Cancer 2006, 9:277-83.

26. Jamshidi $Y$, Gooljar SB, Snieder H, Wang X, Ge D, Swaminathan R, Spector TD, O'Dell SD: SHP-2 and PI3-kinase genes PTPNII and PIK3RI may influence serum apoB and LDL cholesterol levels in normal women. Atherosclerosis 2007, 194:e26-33.

27. Tajima K, Hirose K, Inoue M, Takezaki T, Hamajima N, Kuroishi T: A Model of Practical Cancer Prevention for Out-patients Visiting a Hospital: the Hospital-based Epidemiologic Research
Program at Aichi Cancer Center (HERPACC). Asian Pac J Cancer Prev 2000, I:35-47.

28. Hamajima N, Saito T, Matsuo K, Kozaki K, Takahashi T, Tajima K: Polymerase chain reaction with confronting two-pair primers for polymorphism genotyping. Jpn J Cancer Res 2000, 91:865-8.

29. Higashi H, Tsutsumi R, Fujita A, Yamazaki S, Asaka M, Azuma T, Hatakeyama M: Biological activity of the Helicobacter pylori virulence factor CagA is determined by variation in the tyrosine phosphorylation sites. Proc Natl Acad Sci USA 2002, 99:14428-33

30. Hatakeyama M: Helicobacter pylori CagA - a bacterial intruder conspiring gastric carcinogenesis. Int J Cancer 2006, I 19:1217-23.

31. Mimuro H, Suzuki T, Tanaka J, Asahi M, Haas R, Sasakawa C: Grb2 is a key mediator of Helicobacter pylori CagA protein activities. Mol Cell 2002, 10:745-55

32. Churin Y, Al-Ghoul L, Kepp O, Meyer TF, Birchmeier W, Naumann M: Helicobacter pylori CagA protein targets the c-Met receptor and enhances the motogenic response. J Cell Biol 2003, 16 I:249-55.

33. Tsutsumi R, Higashi H, Higuchi M, Okada M, Hatakeyama M: Attenuation of Helicobacter pylori CagA $\times$ SHP-2 signaling by interaction between CagA and C-terminal Src kinase. J Biol Chem 2003, 278:3664-70.

34. Amieva MR, Vogelmann R, Covacci A, Tompkins LS, Nelson WJ, Falkow S: Disruption of the epithelial apical-junctional complex by Helicobacter pylori CagA. Science 2003, 300:1430-4.

35. Saadat I, Higashi H, Obuse C, Umeda M, Murata-Kamiya N, Saito $Y$, Lu H, Ohnishi N, Azuma T, Suzuki A, Ohno S, Hatakeyama M: Helicobacter pylori CagA targets PARI/MARK kinase to disrupt epithelial cell polarity. Nature 2007, 447:330-3.

36. Ito Y, Azuma T, Ito S, Miyaji H, Hirai M, Yamazaki Y, Sato F, Kato T, Kohli $Y$, Kuriyama M: Analysis and typing of the vacA gene from cagA-positive strains of Helicobacter pylori isolated in Japan. J Clin Microbiol 1997, 35: 17I0-4.

37. Azuma T: Helicobacter pylori CagA protein variation associated with gastric cancer in Asia. / Gastroenterol 2004, 39:97-103.

38. Miki K, Ichinose M, Shimizu A, Huang SC, Oka H, Furihata C, Matsushima T, Takahashi K: Serum pepsinogens as a screening test of extensive chronic gastritis. Gastroenterol Jpn | 987, 22:|33-4|.

39. Biemond I, Kreuning J, Jansen JB, Lamers CB: Serum pepsinogens in patients with gastric diseases or after gastric surgery. Scand J Gastroenterol 1994, 29:238-42.

40. Oksanen A, Sipponen P, Miettinen A, Sarna S, Rautelin H: Evaluation of blood tests to predict normal gastric mucosa. Scand J Gastroenterol 2000, 35:79I-5.

4I. Yanaoka K, Oka M, Mukoubayashi C, Yoshimura N, Enomoto S, Iguchi M, Magari H, Utsunomiya $H$, Tamai $H$, Arii K, Ohata $H$, Fujishiro M, Takeshita T, Mohara O, Ichinose M: Cancer high-risk subjects identified by serum pepsinogen tests: outcomes after 10 . year follow-up in asymptomatic middle-aged males. Cancer Epidemiol Biomarkers Prev 2008, 17:838-45.

42. Inoue M, Kobayashi S, Matsuura A, Hamajima N, Tajima K, Tominaga $\mathrm{S}$ : Agreement of endoscopic findings and serum pepsinogen levels as an indicator of atrophic gastritis. Cancer Epidemiol Biomarkers Prev 1998, 7:26I-3.

43. Suzuki H, Hibi T, Marshall BJ: Helicobacter pylori: present status and future prospects in Japan. J Gastroenterol 2007, 42:I-I5.

44. Sasazuki S, Inoue M, Iwasaki M, Otani T, Yamamoto S, Ikeda S, Hanaoka T, Tsugane S, Japan Public Health Center Study Group: Effect of Helicobacter pylori infection combined with CagA and pepsinogen status on gastric cancer development among Japanese men and women: a nested case-control study. Cancer Epidemiol Biomarkers Prev 2006, I 5: |34|-7.

45. Craanen ME, Dekker W, Blok P, Ferwerda J, Tytgat GN: Intestinal metaplasia and Helicobacter pylori: an endoscopic bioptic study of the gastric antrum. Gut 1992, 33:16-20.

\section{Pre-publication history}

The pre-publication history for this paper can be accessed here:

\section{http://www.biomedcentral.com/1471-230X/9/51/pre}

pub 